\section{Intermedicalidade e protagonismo: a atuação dos agentes indígenas de saúde Munduruku da Terra Indígena Kwatá-Laranjal, Amazonas, Brasil}

\author{
Intermedicality and protagonism: the role of \\ indigenous health agents on the Kwatá-Laranjal \\ Indian Reservation in Amazonas State, Brazil
}

\author{
Intermedicalidad y protagonismo: la actuación \\ de los agentes indígenas de salud en la Tierra \\ Indígena Kwatá-Laranjal, Amazonas, Brasil
}

Daniel Scopel 1

Raquel Paiva Dias-Scopel 1

Esther Jean Langdon 2

\footnotetext{
${ }^{1}$ Instituto Leônidas e Maria Deane, Fundação Oswaldo Cruz, Manaus, Brasil. 2 Programa de Pósgraduação em Antropologia Social, Universidade Federal de Santa Catarina, Florianópolis, Brasil.

Correspondência D. Scopel

Instituto Leônidas e Maria Deane, Fundação Oswaldo Cruz.

Rua Terezina 476, Manaus, AM 69057-070, Brasil. daniel.amazonia@gmail.com
}

\begin{abstract}
This article summarizes the results of an ethnographic study on the role of indigenous health agents on the Kwata-Laranjal Indian Reservation in Borba, Amazonas State, Brazil. The study aims to contribute to understanding the role of indigenous health agents in the expansion of the hegemonic medical model in a context of medical pluralism. The analysis included data from participant observation and interviews conducted from 2009 to 2011. Semi-structured interviews were held to record narratives on their work routine, experiences, and difficulties. The authors conclude that work by indigenous health agents is essential to primary care, and that their role extends beyond technical activities. The Munduruku indigenous health agents hold a key position in the links between indigenous and biomedical knowledge in contexts of intermedicality, emerging as new political actors in interethnic contexts.
\end{abstract}

South American Indians; Community Health Workers; Health of Indigenous Peoples; Medical Anthropology

\section{Resumo}

O artigo sintetiza resultados de pesquisa etnográfica sobre a atuação dos agentes indígenas de saúde (AIS) na Terra Indígena (TI) KwatáLaranjal, Município de Borba, Amazonas, Brasil. Visa a contribuir para a compreensão do papel dos AIS frente à expansão do modelo médico hegemônico em contexto de pluralidade médica. A análise inclui dados de observação participante e entrevistas realizadas de 2009 a 2011. Entrevistas semiestruturadas foram realizadas com objetivo de registrar narrativas sobre a rotina, experiências e dificuldades no trabalho. Concluímos que a atuação dos AIS é essencial para a atenção primária, e seu papel transcende atividades estritamente técnicas. O AIS Munduruku ocupa posição central na articulação entre saberes indígenas e biomédicos em contextos de intermedicalidade e emerge como um novo ator político em contextos interétnicos.

Índios Sul-Americanos; Agentes Comunitários de Saúde; Saúde de Populações Indígenas; Antropologia Médica 


\section{Introdução}

No Brasil, os serviços de saúde indígena estão organizados como Subsistema de Atenção à Saúde Indígena (SASI), vinculados ao Sistema Único de Saúde (SUS). Até 2010, o SASI era administrado pela Fundação Nacional de Saúde (FUNASA), quando passou à Secretaria Especial de Saúde Indígena (SESAI), do Ministério da Saúde. O SASI possui diretrizes preconizadas na Política Nacional de Atenção à Saúde dos Povos Indígenas (PNASPI) 1. A PNASPI enfatiza a necessidade de estratégias para a efetivação dos princípios centrais do SUS “da descentralização, universalidade, equidade, participação comunitária e controle social", mas a partir de uma atenção diferenciada, contemplando "especificidades culturais, epidemiológicas e operacionais” de cada povo ${ }^{1}$ (p. 6).

O processo de construção do modelo de atenção diferenciada teve como ponto de partida o Movimento da Reforma Sanitária Brasileira, nos anos 1980, influenciado pela Conferência Internacional de Alma-Ata sobre Atenção Primária à Saúde em 1978 2,3. Esse processo resultou em esforços para a extensão da cobertura dos serviços de saúde, incluindo estratégias de capacitação de agentes comunitários. No Brasil, a concepção do cargo de agente indígena de saúde (AIS) centrou-se na ideia de que os AIS seriam capazes de ter um olhar interno à comunidade, tanto dos problemas de saúde, como das dinâmicas socioculturais, que influenciariam negativamente os processos de saúde/doença localmente. Dessa forma, previa-se que a capacitação permitiria aos AIS informar as equipes médicas sobre como melhorar a eficácia dos serviços 2,3,4,5. Concomitantemente, poderiam, de uma perspectiva biomédica, ensinar práticas de saúde adequadas às pessoas. Esse enfoque instrumentalista reduz o papel dos AIS ao de facilitador da intervenção e de difusor da ideologia biomédica ${ }^{2}$.

Observamos que os AIS Munduruku ocupam posição central e estratégica na interface entre diferentes formas de atenção, atuando em uma "zona de contato", na qual se produzem saberes mistos, específicos e situacionais 6 , próprios dos sujeitos que atuam em contextos de intermedicalidade, conforme definem Greene 7 e Follér 8. Consideramos que o contexto de intermedicalidade emerge da relação colonial, caracterizado por assimetrias de poder nas relações interétnicas e pela hegemonia da biomedicina. Ao situar os atores sociais nesse contexto, a análise passa a focalizar a capacidade dos AIS de promover articulações, negociações e apropriações entre diferentes saberes.

Verificamos que alguns AIS contavam com longa experiência no cargo, o que lhes conferia habilidade para atuar no contexto de intermedicalidade sem se deterem apenas no modelo biomédico, articulando práticas populares, tradicionais e biomédicas de atenção à saúde e às enfermidades. Os AIS tinham, ainda, conhecimento detalhado sobre práticas de autoatenção ${ }^{9}$ realizadas pelas famílias e sobre itinerários terapêuticos vivenciados por essas pessoas 10 . Nossa pesquisa demonstra que a criação do cargo de AIS entre os Munduruku da Terra Indígena (TI) Kwatá-Laranjal propiciou a emergência de novos sujeitos e espaços sociais de atuação política e que essa atuação não se reduz à aplicação ou reprodução de práticas biomédicas; pelo contrário, repercute na qualidade de vida, segundo o ponto de vista Munduruku.

\section{O povo Munduruku e a metodologia de pesquisa}

Os índios Munduruku, cuja língua pertence ao tronco Tupi, são numerosos e habitam diversas terras indígenas situadas nos estados do Pará, Mato Grosso e Amazonas. Cada uma das terras abriga uma parcela dos Munduruku em situação sociocultural específica. A TI Kwatá-Laranjal, onde realizamos a pesquisa, situa-se no Município de Borba, Estado do Amazonas. Ali, vivem cerca de 2.500 indígenas em 33 aldeias, 21 das quais se situam no rio Canumã e 12, no rio Mari-Mari. Os Munduruku da TI Kwatá-Laranjal falam português; somente os mais velhos falam a língua Munduruku. Este é o segundo maior grupo étnico atendido pelo Distrito Sanitário Especial Indígena (DSEI) Manaus.

O rio Canumã é um afluente do rio Madeira, que atravessa a TI Kwatá-Laranjal. O rio MariMari nasce na TI e deságua no rio Abacaxis. A comunicação hidroviária entre os dois rios recobre grande distância entre as aldeias, de modo que os serviços de atenção à saúde indígena na TI foram estruturados em dois polos-base: Kwatá (rio Canumã) e Laranjal (rio Mari-Mari). Havia, ainda, uma Casa de Apoio à Saúde do Índio (CASAI) na cidade de Nova Olinda do Norte, que servia como casa de passagem e centro administrativo, ao qual estavam vinculados os polos-base.

$\mathrm{O}$ atendimento dos serviços de saúde de atenção primária estava centrado nesses polos, onde ficavam lotadas as Equipes Multidisciplinares de Saúde Indígena (EMSI). A visita às demais aldeias seguia o modelo campanhista, que prioriza a vacinação, organizado, idealmente, em quatro expedições anuais das EMSI. No restante do ano, os serviços eram procurados por demanda espontânea ou encaminhamento dado pelos AIS. Assim, "o AIS é médico, ele é enfermeiro, ele 
é técnico, ele é tudo na aldeia", como relatou um deles. Reiteradamente, ao descrever a situação dos serviços de saúde, lideranças indígenas evocavam a necessidade de melhoria da qualidade da atenção primária. "A saúde Deus deu, o que a gente quer é que melhore o atendimento à saúde", relatou um dos conselheiros locais de saúde.

A organização política interna na TI estrutura-se em torno de conselhos de anciãos e caciques locais, liderados por um cacique geral em cada um dos rios. A hereditariedade é critério principal para escolha das lideranças, especialmente cacique geral, mas outros critérios podem ser utilizados para consenso, como eleição dos caciques locais. A forma como se realizam as decisões em torno de conselhos de lideranças confere coesão política ao grupo.

Os Munduruku no baixo Madeira têm vivenciado um contexto de pluralidade de formas de atenção à saúde que incluem desde o modelo biomédico representado pelo serviço oficial e formas tradicionais de atenção de abordagem xamânica, até a articulação de ambos com saberes populares, mediante um conjunto variado de formas de autoatenção, frequentemente referidas como "tratamentos caseiros" 6,10,11. Essa pluralidade de formas de atenção e praticantes encontra ressonância na cosmografia Munduruku, concebida por meio de interdições e fluxos entre diferentes patamares do cosmo. A circulação dos diversos seres entre os mundos terrestre, subterrâneo, subaquático e o centro da floresta compõe fonte de perigo que pode gerar doenças e morte 6,10,11. Apenas o pajé, ou sacaca, tem a habilidade de circular entre esses mundos, afastando ou promovendo parcerias com os espíritos para buscar a cura. Essa cosmografia orienta a vida na aldeia, de modo que, buscando evitar o perigo de contato com a alteridade radical dos espíritos do ar e do fundo dos rios, as pessoas realizam diversas atividades profiláticas, tais como não frequentar certos lugares, reclusão na menstruação e pós-parto, defumações e banhos com ervas, muitas delas com características de cheiro e propriedades quentes/frias. É importante, também, a noção indígena de corpo como algo fabricado por meio de massagens e puxações, compondo um conjunto de práticas de autotenção, as quais dificilmente poderiam ser instrumentalizadas pelo saber biomédico.

A pesquisa etnográfica foi realizada em três etapas através de observação participante, totalizando cerca de oito meses de trabalho de campo entre os anos de 2009 a 2011. O projeto de pesquisa foi apresentado e aprovado em reuniões do Conselho Distrital de Saúde Indígena e do Conselho Local, realizadas em Manaus e na aldeia As Cobras, respectivamente, sendo submetido à Comissão Nacional de Ética em Pesquisa (CONEP),
Fundação Nacional do Índio (FUNAI), Fundação de Amparo à Pesquisa do Estado do Amazonas (FAPEAM) e ao Conselho Nacional de Desenvolvimento Científico e Tecnológico (CNPq).

Seguindo indicação das lideranças Munduruku, sempre acompanhados por AIS, iniciamos o trabalho de campo. Durante essa primeira etapa, percorremos sete aldeias, nas quais conversas informais e entrevistas foram realizadas com diversos AIS, lideranças indígenas e membros das EMSI, a fim de coletar narrativas sobre o trabalho realizado, dificuldades e especificidades locais. Ficamos hospedados no polo-base Kwatá e na casa do agente indígena de saúde da aldeia Jacaré. Também acompanhamos a participação dos AIS no apoio à consulta médica, remoção de pacientes e organização da atenção primária.

Em uma segunda etapa de campo, optamos por fixar residência na Aldeia Kwatá, ponto de convergência dos AIS do rio Canumã, onde mensalmente entregavam relatórios de atividades e dados de pesagem das crianças. Nesse período, residimos com uma das famílias extensas da aldeia, o que possibilitou a observação sistemática do cotidiano e a participação dos AIS na vida social e na rotina dos serviços de saúde. Desse modo, foi possível verificar, em várias ocasiões, a jornada dos AIS, acompanhando-os, inclusive, em visitas domiciliares, pesagens, auxílio no atendimento do polo-base e em reuniões das EMSI e da comunidade; estivemos presentes, ainda, em outras atividades, como visita a curadores tradicionais, trabalhos voluntários com a Pastoral da Criança, deslocamento até a cidade, no tempo livre para lazer etc. Também realizamos observação participante, visando a descrever e analisar itinerários terapêuticos e práticas de autoatenção indígenas, além da participação dos AIS nesses itinerários. Nesta etapa, realizamos levantamento de dados mais específicos, como educação, gênero, idade, tempo de serviço etc., com o objetivo de traçar o perfil dos AIS Munduruku. O levantamento foi realizado por meio de um breve questionário e entrevistas semiestruturadas com 31 dos 35 AIS que atuavam na TI entre 2009 e 2011. Em complementação, realizamos entrevistas em profundidade com os 12 AIS que contavam maior tempo de permanência no cargo, para obter informações detalhadas sobre experiências e expectativas quanto a cursos de capacitação e formação.

A terceira etapa de campo incluiu a participação dos autores do presente artigo em reunião da União dos Povos Indígenas Munduruku e Saterê (UPIMS), quando foram discutidas especificidades e obstáculos à atuação dos AIS por representantes de todas as aldeias da TI e membros das EMSI. 


\section{Atividade dos AIS e intermedicalidade}

Entre os Munduruku da TI Kwatá-Laranjal, cada agente indígena de saúde era responsável pelo acompanhamento periódico de um conjunto de famílias e, na ausência de outros profissionais, realizavam remoção e acompanhamento daqueles que necessitavam de atendimento médico até a rede do SUS em Nova Olinda do Norte. A agenda de trabalho dos AIS era flexível, sobretudo porque, mesmo assalariados, não poderiam sobreviver na TI sem se dedicar à agricultura e à pesca, atividades diárias necessárias à alimentação, como relatou um dos AIS: "Minha mulher ficava aborrecida, eu saía de casa não deixava nada [peixes], voltava, não trazia nada". Entretanto, dedicavam-se integralmente às EMSI em momentos de consultas médicas ou de campanhas de vacinação. Os AIS da Aldeia Kwatá prestavam apoio aos técnicos de enfermagem na manutenção das atividades do polo-base, de serviços de limpeza à organização de estoques de insumos e arquivos de documentos. Fazia parte da rotina de trabalho informar às EMSI sobre existência de doentes na aldeia. Outra tarefa importante era informar aos moradores quais seriam os dias de consulta, vacinação, coleta ou entrega de resultado de exames.

Segundo Langdon et al. 4, várias etnografias sobre a rotina de trabalho de AIS têm apontado a visita domiciliar como atividade prevista para o cargo, mas que não seria executada de maneira sistemática; é também apontada pelas EMSI como uma das formas de avaliar a qualidade do trabalho dos AIS 4,5,12,13,14,15,16. Diferentemente, em relação aos AIS da Aldeia Kwatá, cumpre destacar que estes realizavam visitas domiciliares regularmente. Foi estabelecido controle formal com a coleta de assinatura em cada casa, e a atividade era vista como importante para acompanhamento de doentes crônicos, aviso sobre agendamentos, consultas e demais atividades das EMSI. Além disso, os agentes efetuavam medições de peso e altura nas crianças de até cinco anos. Havia grande cobrança sobre eles, por parte tanto das EMSI quanto dos demais indígenas, para que realizassem a pesagem na frequência requerida, pois o registro dessa pesagem tinha relação direta com o pagamento do Programa Bolsa Família. Outra atividade era a remoção de doentes, o que implicava viagens perigosas e desgastantes realizadas pelos rios. Era usual que os AIS das aldeias acompanhassem pacientes até o hospital e permanecessem na cidade para acompanhá-los em exames e consultas, ainda que houvesse apoio dos profissionais da CASAI.

As EMSI procuravam instrumentalizar a participação dos AIS nas redes de interações sociais cotidianas para torná-los fontes de informação. Assim, para o médico que atuava na TI KwatáLaranjal, os AIS eram "o olho da equipe", ou, como afirmou uma das técnicas de enfermagem, "são eles que dão todas as informações". As atividades dos agentes eram registradas, por eles mesmos, em formulários enviados mensalmente à CASAI. Esses formulários continham informações acerca de programas de saúde, como controle de hipertensão e diabetes, mas, de fato, não se mantinham registros no polo-base Kwatá, o que, segundo membros das EMSI, decorria da demissão de enfermeiros-chefe. Os AIS da Aldeia Kwatá memorizavam nome, idade, tipo de medicamento e dosagem utilizada no tratamento de hipertensos e diabéticos que moravam na área acompanhada; inclusive, em diferentes ocasiões, observou-se o médico solicitar aos AIS que evocassem da memória informações sobre pacientes. Cabe esclarecer que os AIS não prescreviam, nem ministravam medicamentos. Conforme a Tabela 1, metade dos AIS atuavam há mais de dez anos no cargo e, consequentemente, acumularam experiências de trabalho junto às EMSI, em procedimentos que englobavam desde pesar, aferir pressão, fazer sutura, aplicar injeções (procedimento retirado do conjunto de atividades que realizavam), usar o termômetro, até preencher formulários.

Como participantes do cotidiano de parentes, vizinhos e amigos em processos de doença, os AIS detinham conhecimento detalhado sobre práticas de autoatenção realizadas pelas famílias, sobre itinerários terapêuticos vivenciados por essas pessoas 10. Embora os AIS não fossem reconhecidos como especialistas em práticas indígenas de atenção, também faziam indicação de "remédios do mato" e orientavam doentes que procurassem curadores, pajés e outros especialistas. Tivemos oportunidade de acompanhar mães que foram consultar "pegadores de desmentidura" e "benzedores" por indicação de AIS após a visita domiciliar. Durante essas visitas, observamos AIS indicarem receitas de "remédios do mato" para controlar a hipertensão, enquanto aferiam a pressão ou orientavam sobre o uso da medicação continuada. Eles também conheciam e indicavam receitas de "remédios do mato" para controlar diabetes. Essa prática não era restrita à visita dos AIS, constituindo-se como atividade de autoatenção amplamente difundida, e o uso de remédios caseiros era assunto comum em rodas de conversas.

Nossa observação de AIS indicando consulta a especialistas indígenas ou receitando remédios caseiros permitiu compreender que tais procedimentos baseavam-se em avaliações situacionais, a partir de uma perspectiva inerente ao processo 
Dados do perfil dos agentes indígenas de saúde (AIS) na TI Kwatá-Laranjal. Município de Borba, Estado do Amazonas, Brasil.

\begin{tabular}{|c|c|c|}
\hline Variáveis & $n(N=31)$ & $\%$ \\
\hline \multicolumn{3}{|l|}{ Sexo } \\
\hline Homens & 26 & 84 \\
\hline Mulheres & 5 & 16 \\
\hline \multicolumn{3}{|l|}{ Idade (anos) } \\
\hline $20-30$ & 10 & 32 \\
\hline $31-40$ & 12 & 39 \\
\hline $41-50$ & 7 & 23 \\
\hline$>50$ & 2 & 6 \\
\hline \multicolumn{3}{|l|}{ Tempo de trabalho (anos) } \\
\hline$<3$ & 7 & 23 \\
\hline $4-6$ & 6 & 19 \\
\hline $7-9$ & 2 & 6 \\
\hline$>10$ & 16 & 52 \\
\hline \multicolumn{3}{|l|}{ Escolaridade } \\
\hline Até 5 o ano do Ensino Fundamental & 12 & 39 \\
\hline 6o ao 8o ano do Ensino Fundamental & 17 & 55 \\
\hline 1ㅇa ano do Ensino Médio & 1 & 3 \\
\hline Ensino Médio completo & 1 & 3 \\
\hline \multicolumn{3}{|l|}{ Capacitação } \\
\hline Participaram de cursos de capacitação & 24 & 77 \\
\hline Nunca participaram de cursos de capacitação & 7 & 23 \\
\hline
\end{tabular}

de autoatenção entre os Munduruku, a qual se projetava para além do campo de atuação biomédica. Avaliadas caso a caso, tais indicações e prescrições envolviam múltiplas interpretações sobre o processo de doença, incluindo negociações com a família e, ainda, troca de receitas e modos de preparos características do processo de autoatenção Munduruku. Os AIS, portanto, participavam como um dos muitos interpretadores que influenciavam o itinerário terapêutico, emitindo avaliações sobre tratamentos realizados $\mathrm{e}$ sobre resultados esperados. Também avaliavam a atuação de especialistas, tanto indígenas como biomédicos, durante as visitas domiciliares.

A capacidade de promover a articulação entre diferentes formas de atenção de alguns dos AIS Munduruku demonstra a ambiguidade de seu papel e a impossibilidade de enquadrá-los como meros representantes do modelo biomédico nas aldeias. Vale ressaltar que a atuação dos AIS extrapolava esse âmbito e se inseria em um circuito de trocas e em um campo de negociações próprios à vida social indígena. Gerava-se, assim, impacto direto sobre as práticas de autoatenção Munduruku, as quais não têm necessariamente paralelo com as práticas propostas pelo modelo médico hegemônico 10,11.

\section{Permanência no cargo e protagonismo político}

O tempo de permanência no cargo é um dado relevante no contexto Munduruku. Sugerimos que é importante considerar a relação entre tempo de permanência no cargo e impactos nas ações realizadas em futuros estudos, visando a refletir criticamente sobre processos de seleção e de capacitação.

Os AIS Munduruku estão cientes de sua inserção em uma equipe, em que a divisão de trabalho e a autoridade seguem uma lógica hierárquica fundamentada na especialização profissional. A busca por formação e capacitação por parte dos AIS Munduruku conforma-se ao modelo de legitimação burocrática, mas as motivações também abrangem interesses coletivos de melhoria da qualidade de vida. Desde o primeiro dia da pesquisa de campo, AIS e conselheiros de saúde nos perguntaram sobre experiências-piloto, como o curso de formação técnica para AIS, realizado no Alto Rio Negro 17. Eles tinham expectativa em realizar cursos de capacitação e, principalmente, de formação para elevar a escolaridade. Cabe frisar que, entre os Munduruku, como em outros contextos etnográficos 4,13,14, tais exigências não 
estão restritas a objetivos técnico-operacionais, compondo um conjunto amplo de demandas por investimentos compreendidos como parte essencial para a melhoria da atenção primária.

Nas entrevistas em profundidade, pedimos aos AIS Munduruku atuantes há mais de dez anos para relacionar quais cursos de capacitação haviam frequentado. Alguns deles mantinham certificados que comprovavam capacitações realizadas nas décadas 1970 e 1980, como de atendente de enfermagem, com experiência, inclusive, de estágio em hospital. Em 1993, a associação indígena dos Munduruku se articulou com a Igreja Católica e com a Coordenação das Organizações Indígenas da Amazônia Brasileira (COIAB) para realizar curso específico para AIS. Outros cursos para capacitar os agentes, conduzidos por instituições como a Universidade Federal do Amazonas, o Conselho Indigenista Missionário, FUNAI e a Pastoral da Criança, aconteceram nos anos de 1994, 1995, 1998 e 1999. Esse quadro demonstra que os AIS atuantes há mais de dez anos (52\%), apesar da baixa escolaridade, haviam recebido capacitações diversas.

Os AIS Munduruku reclamavam da descontinuidade de capacitações realizadas sob a gestão da FUNASA. A fundação havia proposto um curso dividido em módulos, que nunca foi concluído; apenas alguns módulos foram realizados, e o último encontro ocorreu em 2005. Entre 2005 e 2010, os agentes relataram que tiveram apenas cursos breves e específicos, incluindo um sobre DST/AIDS, organizado pela Secretaria Municipal de Saúde, em conjunto com a Fundação Alfredo da Matta. O curso havia sido realizado como parte de uma campanha para detecção de sífilis por meio de testes rápidos.

A maioria dos AIS com menos de seis anos de trabalho não recebeu qualquer capacitação fora da rotina. Nesse caso, os mais novos obtinham conhecimento sobre como atuar via outros membros das EMSI e, principalmente, de maneira informal, ao acompanhar o trabalho dos agentes mais experientes. Seguiam, portanto, o modo tradicional de aprendizado indígena, que privilegia a prática cotidiana como forma de desenvolver habilidades 10 .

Embora a PNASPI faça referência conjunta à formação e à capacitação, entre os Munduruku da TI Kwatá-Laranjal, verificou-se que nenhuma formação havia sido realizada "direcionada para a construção de competências/habilidades, visando facilitar o prosseguimento da profissionalização nos níveis médio (técnico) e superior (tecnológico)" 1 (p. 14). Esse fato implicou demanda explícita por oportunidades para elevar a escolaridade, estimulando alguns dos AIS da Aldeia Kwatá, por iniciativa própria, a matricularem-se no Ensino para Jovens e Adultos (EJA). Um deles era, ainda, autodidata, estudando em livros do Ensino Fundamental e pequenas enciclopédias sobre plantas medicinais de uso popular, evocando que seus estudos eram necessários para atuação como AIS, não só para orientar a comunidade, como também para preencher documentos.

Na Aldeia Kwatá, o processo de seleção de novos AIS passou pela eleição de uma entre duas candidatas; na ocasião, votaram as pessoas que faziam parte da área de abrangência de trabalho da vaga ao cargo. O resultado da eleição foi ratificado pelo cacique, apesar de a família deste ter apoiado a candidata perdedora. A nova agente indígena de saúde iniciou o trabalho acompanhando visitas domiciliares de uma agente mais experiente, por cerca de um mês, e teve treinamento com as técnicas de enfermagem do polobase. A habilidade em manejar um aferidor de pressão digital foi avaliada com grande curiosidade pelos moradores da casa em que estávamos hospedados, quando da primeira visita domiciliar da nova agente.

Em geral, na contratação de novos AIS, percebia-se que a escolaridade tornava-se critério cada vez mais importante, tanto por parte das EMSI, quanto da comunidade, se bem que a indicação de pessoas para o cargo não seguisse regras definidas, sendo apenas necessário consenso entre os indígenas. Apesar disso, a escolaridade era considerada critério relevante. $\mathrm{Na}$ eleição que acompanhamos, ambas as candidatas estavam matriculadas na mesma turma do EJA, concluindo o Ensino Fundamental. Cabe notar que, além dos professores indígenas, eram poucos os indígenas que tinham formação no Ensino Médio. Estes, em geral, eram jovens solteiros, cujos pais haviam financiado os estudos em cidades próximas à TI, ou em Manaus; ou seja, compunham um perfil que destoava da maioria dos adultos, que eram pessoas casadas, com filhos, cujas famílias tinham atividades orientadas para a agricultura e a pesca.

Os AIS entrevistados percebiam que a ausência de capacitações nos últimos anos havia sido concomitante à contínua perda de atribuições do cargo. Historicamente, até meados dos anos 1990, agentes indígenas tinham relativa autonomia no exercício de práticas biomédicas, já que a FUNAI os capacitava para realizarem procedimentos como aplicar injeções ou distribuir medicamentos, inclusive antibióticos. Com a PNASPI e a crescente presença de outros profissionais de saúde nas aldeias, práticas anteriormente realizadas pelos AIS ficaram restritas aos que ocupavam cargos com formação técnica e biomédica das EMSI. Essa perda de autonomia era percebida pelos AIS Munduruku como desempoderamento do cargo. 
Para demais moradores da aldeia, a perda de autonomia representava contradição com expectativas sobre atuação dos AIS, pois consideravam o cargo uma posição privilegiada no acesso a bens e a serviços biomédicos, ao passo que o desempoderamento era expresso como falta de habilidade individual dos AIS, não sendo percebido como perda de atribuição originada pela divisão do trabalho nas EMSI. Além disso, escassez e racionamento de recursos implicavam avaliações negativas sobre o serviço de saúde e sobre a atuação dos AIS, visto que faltavam profissionais, medicamentos, equipamentos e combustível na proporção suficiente para o trabalho das EMSI.

Apesar do contexto de precariedade da atenção primária, a experiência dos AIS Munduruku sublinha que o protagonismo desses agentes é balizado pelas dinâmicas socioculturais dos contextos locais, e não apenas pelas lógicas institucionalizadas através do modelo médico hegemônico. Verificou-se que alguns AIS valeram-se do cargo para promover negociações políticas, indo além das atividades técnicas demandadas pelas EMSI, atuando junto a setores da Igreja Católica, negociando com a prefeitura municipal e com partidos políticos, assumindo, adicionalmente, papéis dentro da estrutura prevista nos Conselhos Local e Distrital de Saúde Indígena.

Durante a atuação da Pastoral da Criança, entre 2010 e 2011, os AIS Munduruku auxiliaram as missionárias em atividades diversas, como pesagem das crianças, treinamento de outros indígenas para trabalhar na Pastoral e nas visitas às famílias. Parte do treinamento desses voluntários consistia em aplicar questionário em visitas domiciliares. Logo, além de guiar missionárias nas visitas, alguns dos AIS da Aldeia Kwatá auxiliavam na aplicação do questionário da Pastoral da Criança, fornecendo dados sobre a família (números de membros, ocupação etc.). Cumpre esclarecer que a presença de missionárias católicas na aldeia fora uma demanda dos indígenas, percebida como fruto do prestígio das lideranças indígenas perante a diocese.

É preciso destacar que os AIS Munduruku atuavam junto aos caciques, isto é, o cargo não se inseria apenas na hierarquia das EMSI, sendo, também, incorporado ao sistema político Munduruku. Assim, os AIS eram convocados pelos caciques a participar de reuniões e assumir um papel ativo nelas. Conforme observamos em diferentes ocasiões, cabia aos agentes sintetizar a situação dos serviços de saúde da aldeia em que atuavam, de modo que a habilidade na comunicação oral compunha um importante indicador indígena da capacidade de atuação política de um líder. Verificamos, portanto, que a atuação dos AIS extrapolava o âmbito das atividades es- tritamente técnicas da EMSI, já que exerciam um papel importante nas reuniões dos Conselhos Local e Distrital de Saúde Indígena.

Tal quadro difere do que foi relatado por Langdon \& Diehl 18 em outro contexto etnográfico, no qual as reuniões desses conselhos não tinham a efetiva participação dos moradores. Entre os Munduruku da TI Kwatá-Laranjal, os AIS possuíam legitimidade para participar das reuniões do Conselho Local e assim procediam ao acompanhar os conselheiros e os caciques das aldeias, ao relatar problemas e expor demandas que, em geral, referiam-se às falhas operacionais e de gestão do subsistema. Entre as falhas, destacam-se o não cumprimento dos planos plurianuais aprovados; a falta de medicamentos, combustível e equipamentos simples, como balanças e trenas; edificações, barcos e equipamentos sem manutenção; rotatividade e falta de profissionais nas EMSI; excesso e duplicidade de formulários; perda de documentos; atrasos salariais e ausência de estratégias de formação e capacitação dos AIS. Esses problemas compunham o cotidiano das EMSI e dos AIS, gerando alto grau de incerteza e improvisação na atenção primária, fato amplamente discutido pelas lideranças indígenas e assembleias locais.

Na TI Kwatá-Laranjal, ambos os conselheiros distritais eram AIS nas aldeias de origem e valiam-se do cargo para atuar frente aos governos municipal e estadual, indicando que essa atuação abrangia também estruturas políticas externas à TI. Nossa pesquisa revelou que o cargo de agente indígena de saúde permitia protagonismo político tanto dentro do âmbito do controle social promovido pelo serviço de saúde, quanto fora dele. Esse aspecto é relevante, pois foi em decorrência de uma série de reuniões com gestores de âmbito municipal, Ministério Público e FUNASA, que AIS e demais lideranças Munduruku conseguiram negociar a aplicação de recursos de acordo com prioridades elencadas pelos agentes. Assim, saldos financeiros de ações planejadas e não executadas em anos anteriores, que estavam disponíveis no Município de Borba, em meados de 2010, foram utilizados na compra de kits e lanchas para uso dos AIS em 2011. Esses kits continham itens considerados importantes para a atuação dos agentes, incluindo uniforme, termômetro, fita métrica e aparelho para medir pressão arterial. A aquisição das lanchas foi uma das prioridades elencadas para melhorar as condições de remoção de pacientes e ficariam sob a responsabilidade dos AIS de cada aldeia.

Além de instrumentalização dos recursos biomédicos para fins políticos internos aos grupos indígenas, conforme assinalada por Garnelo 19 e por Cardoso 20, o protagonismo político dos 
AIS Munduruku comporta uma importante dimensão relacional e exterior a essa sociedade. Ao interagir com as lideranças Munduruku, o protagonismo político dos AIS colabora com a função de garantir a autodeterminação da sociedade indígena no contexto pluriétnico, consoante com a atenção primária nos moldes da proposta de Alma-Ata, apresentando-se como questão central para as políticas públicas para saúde dos povos indígenas 20,21 .

\section{Considerações finais}

Na TI Kwatá-Laranjal, a maioria dos AIS trabalhava há mais de dez anos no cargo, acumulando experiências e habilidades importantes para a atuação no serviço de saúde e também no âmbito político. Os agentes tinham papel central na promoção da atenção primária ao desempenharem atividades que incluíam remoção e acompanhamento de pacientes, visitas domiciliares, programas de controle de doenças crônicas e acompanhamento nutricional das crianças, bem como indicação de especialistas indígenas e "remédios caseiros". Também atuaram na capacitação em serviço dos AIS recém-contratados e tiveram participação ativa em reuniões do Conselho Local e Distrital de Saúde, nas negociações junto aos políticos locais para reivindicar recursos financeiros, ou em reuniões com órgãos de diferentes esferas da administração pública. De modo geral, os AIS com longa experiência no cargo demostravam habilidades para atuar no contexto de intermedicalidade, valendo-se da negociação de interpretações sobre a doença, suas causas e possíveis terapêuticas, além de serem participantes da vida cotidiana e dos processos sociais de autoatenção à saúde e às enfermidades 9 .

Os AIS Munduruku acumularam habilidades e capacidades que não se reduzem ao manejo de saberes e procedimentos biomédicos; adicionalmente, eles têm uma atuação política decisiva no contexto de pluralidade médica, participando diretamente de processos de negociações por melhoria da qualidade dos serviços de saúde. Tais habilidades reforçam a necessidade de se investir em estudos que focalizem a agência e as práticas cotidianas dos AIS, que promovem a articulação entre diferentes formas de atenção à saúde, inclusive a autoatenção, conforme sugerem Moura-Pontes \& Garnelo 14.

Por um lado, nossa pesquisa demonstrou que os AIS Munduruku percebem o desempoderamento do cargo na inserção das EMSI. Por outro, verificamos que a emergência e consolidação do cargo de AIS abriu a possibilidade para o empoderamento de sujeitos em uma complexa rede formada pelos Munduruku na interação com o poder estatal. O presente estudo também aponta que a atuação dos AIS Munduruku repercute nas dinâmicas políticas locais, por meio de atividades que estão além daquelas restritas à inserção nas EMSI. Apesar disso, a valorização da escolaridade se manifestava localmente, por intermédio das expectativas dos próprios AIS em obter capacitação e formação profissional como requisito para manejar melhor as atividades previstas pelo modelo biomédico de atenção. Essas expectativas expressam a intencionalidade desses atores em se inserir com mais efetividade na hierarquia profissional das EMSI. É preciso considerar que tais expectativas emergem na interface com o modelo médico hegemônico e a partir da própria dinâmica da política interna da TI Kwatá-Laranjal.

Apesar das dificuldades, incertezas e precariedade do cenário da atenção biomédica às populações indígenas, torna-se cada vez mais necessário dar visibilidade à agência de atores locais, em face das características estruturais do modelo médico hegemônico; em particular às potencialidades dos AIS como atores políticos emergentes do contexto interétnico e a posição central que ocupam no campo de forças da intermedicalidade. 


\section{Resumen}

Este artículo sintetiza los resultados de una investigación etnográfica sobre la actuación de los agentes indígenas de salud (AIS), en la tierra indígena KwataLaranjal, Amazonas, Brasil. Dicha investigación procura contribuir a la reflexión sobre el papel que los AIS desempeñan, frente a la expansión del modelo médico hegemónico, en un contexto de pluralidad médica. Los datos fueron obtenidos a partir de observación participante y de entrevistas realizadas entre los años 2009 y 2011. Las entrevistas semi-estructuradas se llevaron a cabo con el fin de registrar la rutina, experiencias y dificultades en el trabajo. Concluimos que el papel de los AIS es fundamental para los servicios de atención primaria, y que su actuación trasciende las actividades técnicas, dado que los AIS Munduruku realizaban un importante papel como articuladores entre los saberes biomédicos e indígenas en contextos de intermedicalidad, y actuando como nuevos actores políticos en contextos interétnicos.

Indios Sudamericanos; Agentes Comunitarios de Salud; Salud de Poblaciones Indígenas; Antropología Médica

\section{Colaboradores}

D. Scopel participou da análise e interpretação dos dados; pesquisa de campo; redação e revisão crítica relevante do conteúdo intelectual; e aprovação da versão final. R. P. Dias-Scopel participou da concepção, coordenação do projeto; análise e interpretação dos dados; pesquisa de campo; redação e revisão crítica relevante do conteúdo intelectual; e aprovação da versão final. E. J. Langdon participou da concepção do projeto e revisão crítica relevante do conteúdo intelectual; e aprovação da versão final.

\section{Agradecimentos}

Agradecemos aos Munduruku da TI Kwatá-Laranjal, especialmente ao Cacique Manoel Cardoso Munduruku, pela colaboração e suporte na realização da pesquisa de campo; à antropóloga Carolina Portela, pela tradução do resumo para espanhol. Agradecemos, também, à Fundação de Amparo à Pesquisa do Amazonas (FAPEAM) e ao INCT Brasil Plural, pelo financiamento da pesquisa. D. Scopel agradece ao CNPq pela bolsa de pós-doutorado. 


\section{Referências}

1. Fundação Nacional de Saúde. Política Nacional de Atenção à Saúde dos Povos Indígenas. 2a Ed. Brasília: Fundação Nacional de Saúde; 2002.

2. Dias-Scopel RP. O agente indígena de saúde Xokleng: por um mediador entre a comunidade indígena e o Serviço de Atenção Diferenciada à Saúde - uma abordagem da antropologia da saúde [Dissertação de Mestrado]. Florianópolis: Programa de Pós-graduação em Antropologia Social, Universidade Federal de Santa Catarina; 2005.

3. Erthal RMC. A formação do agente de saúde indígena Tikúna no Alto Solimões: uma avaliação crítica. In: Coimbra Jr. CEA, Santos RV, Escobar AL, organizadores. Epidemiologia e saúde dos povos indígenas no Brasil. Rio de Janeiro: Editora Fiocruz; 2003. p. 197-215.

4. Langdon EJ, Diehl EE, Dias-Scopel RP. O papel e a formação dos agentes indígenas de saúde na atenção diferenciada à saúde dos povos indígenas brasileiros. In: Teixeira CC, Garnelo L, organizadores. Saúde indígena em perspectiva: explorando suas matrizes históricas e ideológicas. Rio de Janeiro: Editora Fiocruz; 2014. p. 213-39.

5. Garnelo L, Pontes AL, Stauffer A. Profissionalização indígena no campo da saúde: desafios para a formação técnica de Agentes Indígenas de Saúde. In: Garnelo L, Pontes AL, organizadores. Saúde indígena: uma introdução ao tema. Brasília: Secretaria de Educação Continuada, Alfabetização, Diversidade e Inclusão, Ministério da Educação; 2012. p. 265-88.

6. Scopel D, Dias-Scopel RP, Wiik FB. Cosmologia e intermedicalidade: o campo religioso e a autoatenção às enfermidades entre os índios Munduruku do Amazonas, Brasil. Tempus: Actas de Saúde Coletiva 2012; 6(1). http://www.tempus.unb.br/ index.php/tempus/article/viewArticle/1141.

7. Greene S. The shaman's needle: development, shamanic agency, and intermedicality in Aguaruna Lands, Peru. Am Ethnol 1998; 25:634-58.

8. Follér M-L. Intermedicalidade: a zona de contato criada por povos indígenas e profissionais de saúde. In: Langdon EJ, Garnelo L, organizadores. Saúde dos povos indígenas: reflexões sobre antropologia participativa. Rio de Janeiro: Contra Capa; 2004. p. 129-48.

9. Menéndez EL. Sujeitos, saberes e estruturas: uma introdução ao enfoque relacional no estudo da saúde coletiva. São Paulo: Editora Hucitec; 2009.

10. Scopel D. Uma etnografia sobre a pluralidade de modelos de atenção à saúde entre os índios Munduruku na Terra Indígena Kwatá Laranjal, Borba, Amazonas: práticas de autoatenção, xamanismo e biomedicina [Tese de Dutorado]. Florianópolis: Universidade Federal de Santa Catarina; 2013.
11. Dias-Scopel RP. A cosmopolítica da gestação, parto e pós-parto: práticas de autoatenção e processo de medicalização entre os Índios Munduruku [Tese de Doutorado]. Florianópolis: Universidade Federal de Santa Catarina; 2014.

12. Dias-Scopel RP, Langdon EJ, Scopel D. Expectativas emergentes: a inserção do agente indígena de saúde Xokleng na equipe multidisciplinar de saúde indígena. Tellus 2007; 13:51-72.

13. Diehl EE, Langdon EJ, Dias-Scopel RP. Contribuição dos agentes indígenas de saúde na atenção diferenciada à saúde dos povos indígenas brasileiros. Cad Saúde Pública 2012; 28:819-31.

14. Moura-Pontes AL, Garnelo L. La formación y el trabajo del agente indígena de salud en el Subsistema de Salud Indígena en Brasil. Salud Pública Méx 2014; 56:386-92.

15. Langdon EJ, Diehl EE, Wiik FB, Dias-Scopel RP. A participação dos agentes indígenas de saúde nos serviços de atenção à saúde: a experiência em Santa Catarina, Brasil. Cad Saúde Pública 2006; 22:2637-46.

16. Novo MP. Saúde e interculturalidade: a participação dos Agentes Indígenas de Saúde/AIS do Alto Xingu. Revista de Antropologia Social dos Alunos do PPGAS-UFSCar 2009; 1:122-47.

17. Garnelo L, Rocha E, Peiter P, Sampaio S, Santos E, Pontes AL. Formação técnica de agente comunitário indígena de saúde: uma experiência em construção no Rio Negro. Trab Educ Saúde 2009; 7:373-85.

18. Langdon EJ, Diehl EE. Participação e autonomia nos espaços interculturais de saúde indígena: reflexões a partir do sul do Brasil. Saúde Soc 2007; 16:19-36.

19. Garnelo L. Poder, hierarquia e reciprocidade: saúde e harmonia entre os Baniwa do Alto Rio Negro. Rio de Janeiro: Editora Fiocruz; 2003.

20. Cardoso MD. Políticas de saúde indígena e relações organizacionais de poder: reflexões decorrentes do caso do Alto-Xingú. In: Langdon EJ, Garnelo L, organizadoras. Saúde dos povos indígenas: reflexões sobre antropologia participativa. Rio de Janeiro: Contra Capa; 2004. p. 149-69.

21. Langdon EJ. A tolerância e a política de saúde do índio no Brasil: são compatíveis os saberes biomédicos e os saberes indígenas? In: Grupioni LDB, Vidal LB, Fischmann R, organizadores. Povos indígenas e tolerância. São Paulo: Edusp; 2001. p. 157-65.

Recebido em 13/Set/2014

Versão final reapresentada em 22/Mai/2015 Aprovado em 03/Jun/2015 